Nig. J. Biotech. Vol. 38 (1) : 68-73 (June 2021)

ISSN: 01891731

Available online at

http://www.ajol.info/index.php/njb/index

and www.biotechsocietynigeria.org

DOI: https://dx.doi.org/10.4314/njb.v38i1.8

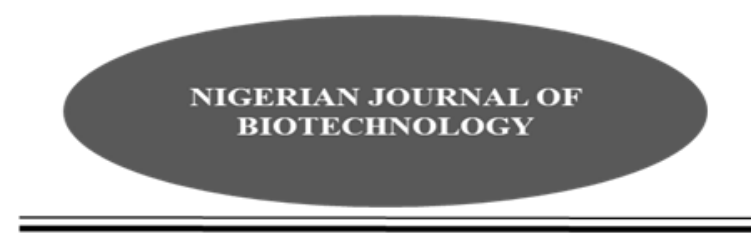

\title{
Isolation Of Mycotoxi genic Fungi And Quantification Of Aflatoxins From Bean Flours Sold In Abeokuta Nigeria
}

\author{
${ }^{1}$ Badmos A. O., ${ }^{1}$ Olonode, S., ${ }^{1}$ Oni E. O. and ${ }^{1}$ Adeleye, T.M \\ Department of Microbiology, Federal University of Agriculture, Abeokuta. Nigeria.
}

\begin{abstract}
The recent increase in consumers' preference for commercially sold bean flour necessitated the need to determine associated mycoflora and quantify the toxin production by the isolates, since several fungal genera have been associated with bean grains. Four fungal genera were isolated from fifteen beans flour samples sourced from various markets in Abeokuta by serial dilutions and pour plates methods on Potato Dextrose Agar (PDA) plates. Distinct colonies were transferred to Methyl Red Dessicated Coconut Agar (MRDCA) plates to identify toxin- producing isolates and High Performance Liquid Chromatography (HPLC) was used for aflatoxin quantification from the bean flour samples. The isolated fungal genera were, Aspergillus (60\%), Fusarium (10\%), Rhizopus $(15 \%)$ and Mucor (5\%). Nine of the fifteen samples were found positive for aflatoxigenic organisms and also produced aflatoxins that ranged from 0.006 to $0.151 \mathrm{ng} / \mathrm{kg}$. The presence of toxin- producing organisms in the bean flour which is above the acceptable standard is a red flag that must be addressed vigorously if public health is a priority.
\end{abstract}

Keywords: Aflatoxin, Food contamination, High Performance Liquid Chromatography (HPLC), Public health, Staple cereals.

Corresponding author Email: badmosao@funaab.edu.ng :Tel. +2348161540902/ +2348057118367

Introduction

The diets of almost all the people residing in emergent nations comprise mainly starchy roots, cereals, and little legumes. Animal sources of protein, which are used as substitutes for these diets are not cheap and affordable, and are sometimes out of reach for families who are low income earners (Kolapo and Oladimeji, 2018). However, grain legumes serve as a cheap source of proteins to an appreciable number of the population in tropical countries (Gesinde et al., 2008).

Beans are classified as one of the leguminous plants whose seeds emanate from flowering plants in the Fabaceae family, and several bean seeds grow in a jacket- like pod that houses them. These pods mature from flowers. The bean seeds possess chemicals such as amino acids that integrate to create protein and also assist in building body muscle. There are several varieties of beans cultivated around the world, but native to Nigeria are the honey beans (ewa oloyin) and the drum beans popularly referred to as pewu and are usually available all year round.
An increasing number of consumers in Nigeria conveniently opt for processed derivative products from legumes more than the actual grains to have a change of meal while still using their favorite legume and to reduce stress of having to manually change it to the desirable meal. Beans fall in the category of legume crops with great prospects and thus can be manipulated and processed into the blended form for a variety of delicacies (Oranusi and Braid, 2015). In Nigeria, it is conveniently used to make Moi-moi (bean cake) and bean balls (Akara).

Several fungal genera such as Alternaria, Aspergillus, Aphanomyces, Curvularia , Fusarium, Penicillium and Rhizopus species have been reported to be associated with foliar and root diseases on beans, peas and other legumes (Abdulwahab et al., 2015). They successfully colonize the grains and alter its nutritional properties (Samson, 2017). Some of the species of these fungi produce toxins such as the aflatoxins, which can be carried over to the derivative products. Aflatoxins are poisonous secondary metabolites produced by fungi species mainly by 
Badmos et al. / Nig. J. Biotech. Vol. 38 Num. 1 : 68-73(June 2021)

Aspergillus flavus, A. parasiticus and A.nomius and have been reported by Oluwafemi and Taiwo, (2004) to have detrimental effects on humans, food crops, animals and feeds. Aflatoxins B1, B2, G1 and $\mathrm{G} 2$ are most prevalent in natural environments and their toxic nature has made them important mycotoxins in foods and feeds (Makun et al., 2012). Attention has not been paid to the extent of aflatoxin contamination in bean derivatives such as bean flour in Nigeria. Consequently, there is dearth of information on aflatoxigenic fungi and toxins associated with bean flour in Nigeria. It is the aim of this study to isolate aflatoxigenic fungi and quantify the level of aflatoxins in some commercially sold bean flour in Abeokuta, Ogun state Nigeria with7. $1475^{\circ} \mathrm{N}, 3.3619^{\circ} \mathrm{E}$ coordinates.

\section{Materials and Methods}

\section{Collection of Samples}

Fifteen frequently purchased brands of commercially sold bean flour were sourced from different stores in Abeokuta markets and transported to the laboratory for analysis. Homemade beans that was made into bean flour were used as the control experiment.

\section{Isolation of Fungi in the Beans Flour Samples}

Enumeration of fungal load in the samples was done using the pour plate method. Serial dilution was carried out by adding $1 \mathrm{~g}$ of bean flour into $10 \mathrm{ml}$ of sterilized peptone water in a test tube, which served as the stock solution. Afterwards, $1 \mathrm{ml}$ was pipetted from the stock solution and added to $9 \mathrm{ml}$ of peptone water in another tube on the rack, which made it up to $10 \mathrm{ml}$ and the same procedure was repeated for nine more tubes on the rack. The third and fifth dilutions were dispensed in a petri dish and Potato Dextrose Agar (PDA) was added and incubated at $28^{\circ} \mathrm{C}$ for seven days while each dilution was replicated five times. Distinct colonies were isolated and sub-cultured to obtain pure cultures that were stored on Potato Dextrose Agar slants for characterization and identification.

\section{Identification and Characterization of Fungal Isolates}

Isolates were identified macroscopically using morphological and cultural characteristics as highlighted by Klich (2002), through colour, elevation, shape on plates and pigmentation. Microscopic identification was also done by mounting the vegetative part of the fungus on a microscopic slide containing $95 \%$ ethanol, a drop of Lactophenol Cotton Blue stain was added to the slide after the ethanol had almost evaporated, covered with a cover slip and examined under an objective lens.

\section{Screening for Aflatoxin Production of Fungal isolate}

The isolates were cultured on Methyl Red Desiccated Coconut Agar (MRDCA) as formulated by Atanda et al., (2011) and incubated at room temperature in a dark cupboard for three days. The growth on the plate was exposed to $365 \mathrm{~nm}$ Ultraviolet light to observe fluorescence produced by the isolates.

Quantification of Aflatoxin from Beans Flour using High Performance Liquid Chromatography (HPLC).

Aflatoxin standards were obtained from Chromogen International Limited, Lagos, Nigeria. For each aflatoxin, a stock solution was prepared in acetonitrile and stored at $20^{\circ} \mathrm{C}$. The solution was calibrated spectrophotometrically at $350 \mathrm{~nm}$ (AOAC, 2000). The working standard solution was prepared after evaporation of an aliquot $(100 \mathrm{ml})$, the stock solution under nitrogen and redissolution in chloroform $(10 \mathrm{ml})$ by ultrasonication. An aliquot $(100 \mathrm{ml})$ of this solution was evaporated under nitrogen and redissolved in the HPLC mobile phase to obtain calibrate solutions at individual concentrations of AFB1, AFB2, AFG1 and AFG2.

\section{Results}

Table 1: Macroscopic and Microscopic Features of Isolated Fungal Isolates from Bean Flour Samples

\begin{tabular}{|c|c|c|c|c|}
\hline $\mathrm{S} / \mathrm{N}$ & Isolate Code & $\begin{array}{l}\text { Microscopic } \\
\text { Features }\end{array}$ & Macroscopic Features & Probable Microbes \\
\hline 1 & $\mathrm{BF} 1$ & $\begin{array}{l}\text { Smooth walled } \\
\text { conidiophores }\end{array}$ & Dark green & Aspergillus fumigatus \\
\hline 2 & $\mathrm{BF} 2$ & $\begin{array}{l}\text { Non-septate } \\
\text { conidiophores }\end{array}$ & Woody white & Fusarium $s p$ \\
\hline 3 & BF3 & $\begin{array}{l}\text { Large globose } \\
\text { conidiophores }\end{array}$ & Black & Aspergillus niger \\
\hline 4 & BF4 & $\begin{array}{l}\text { Budding Yeast } \\
\text { Cells }\end{array}$ & Creamy white & Saccharomyces cerevisae \\
\hline 5 & BF5 & $\begin{array}{l}\text { Hyphae without } \\
\text { Rhizoids }\end{array}$ & cotton-like colonies & Mucor sp. \\
\hline
\end{tabular}




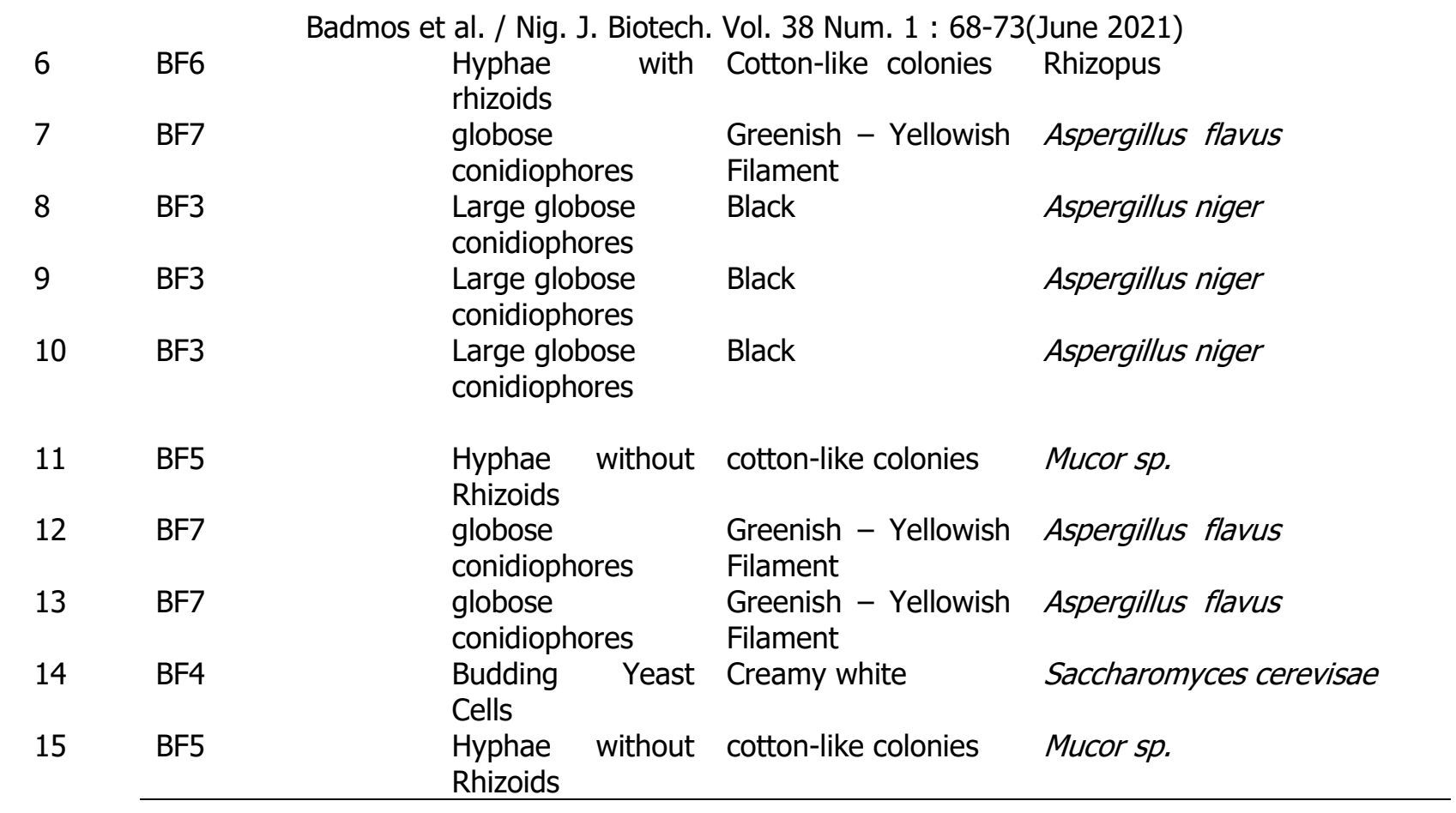

Table 1 shows the macroscopic and microscopic features of fungal isolates in bean flour samples. Microscopic features revealed the isolated mould globose and conidiophores features, while the macroscopic features shows the colour ranging from yellow to white and green

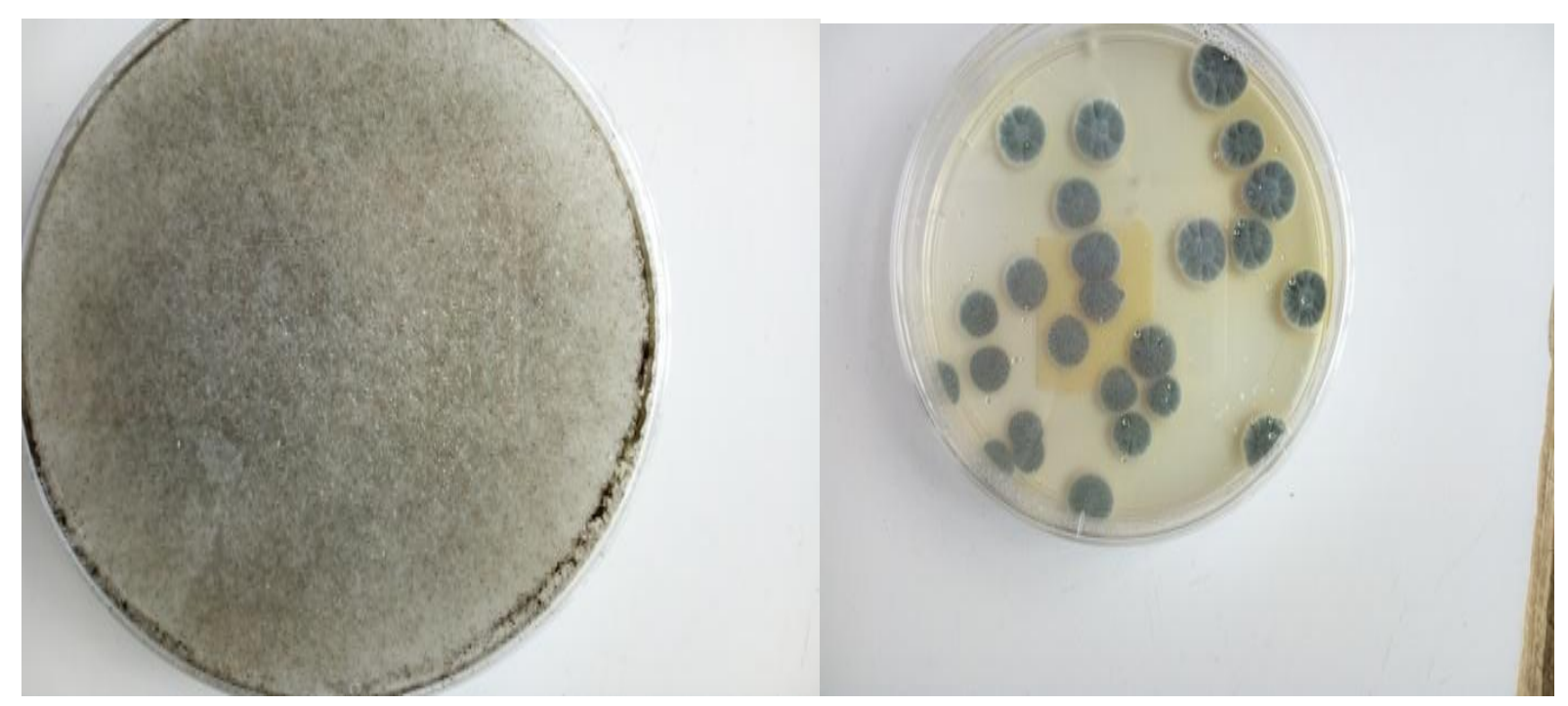

Plate 1: Rhizopus sp. 


\section{Plate 3: Mucor}

Plate 4: Saccharomyces cerevisiae

Plate 1 to 4 shows the macroscopic view of the dominant fungal genera isolated from the Beans flour sample

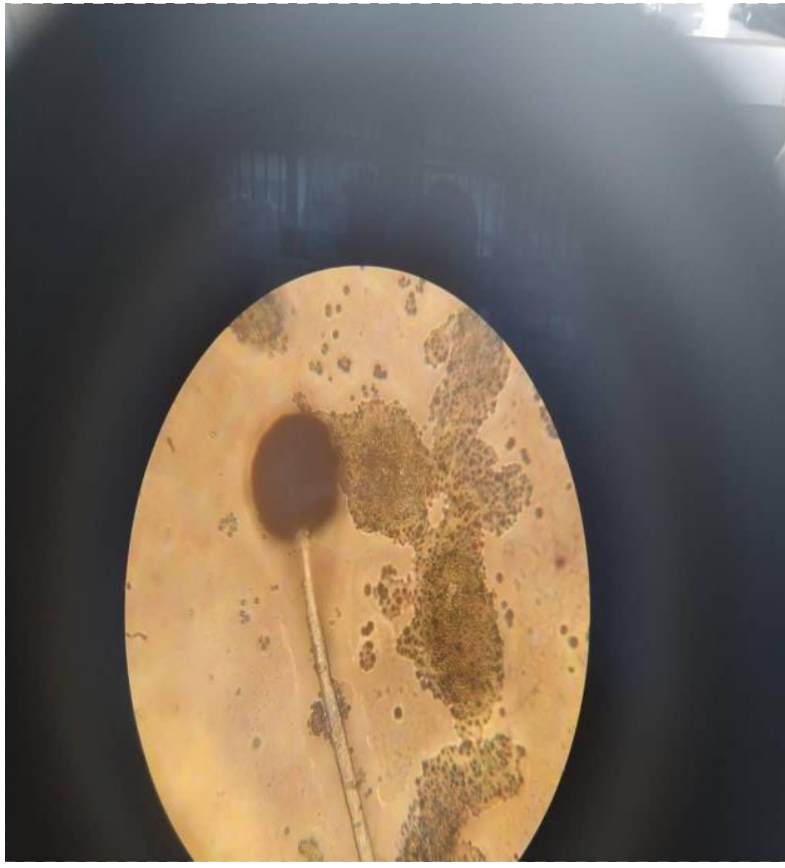

Plate 5 Hyphae without Rhizoid

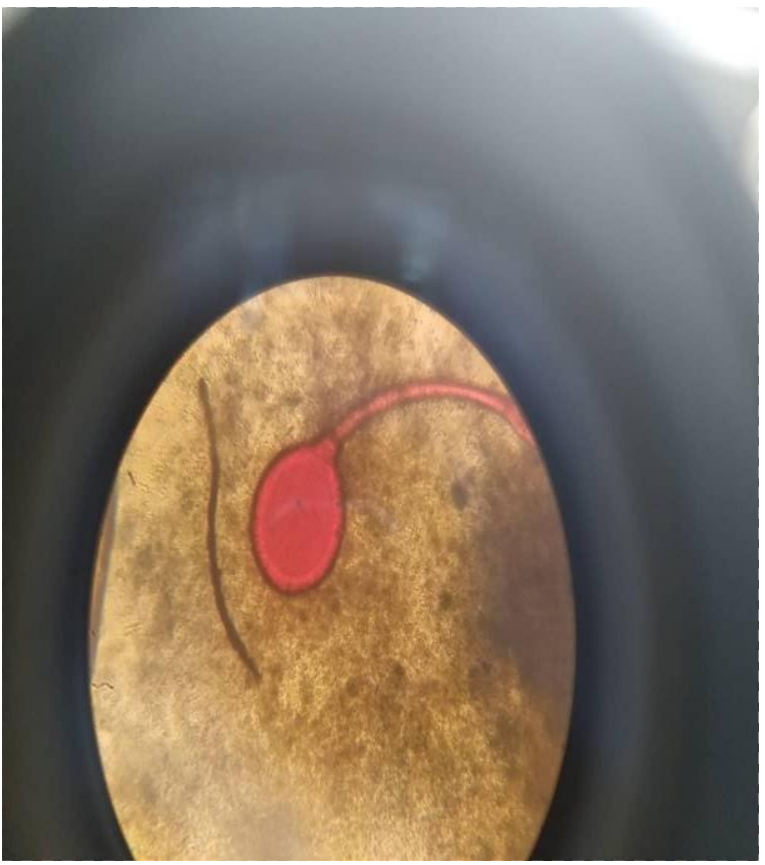

Plate 6 Smooth walled conidiophores

Plate 5 and 6 shows the microscopic views of isolated Aspergillus species.

Table 2: Toxin Production Potentials of Fungal Isolates from Beans Flour

\begin{tabular}{lccc}
\hline ISOLATE CODE & ORGANISM & TOXIN PRODUCTION & TOXIN PRODUCED \\
\hline BF1 & Aspergillus fumigatus & Positive & Aflatoxin \\
BF2 & Fusarium spp. & Positive & Fumonisin \\
BF3 & Aspergillus niger & Positive & Aflatoxin \\
BF7 & Aspergillus flavus & Positive & Aflatoxin \\
BF4 & Saccharomyces cerevisae & Negative & None \\
BF5 & Mucorspp & Negative & None \\
BF6 & Rhizopus spp. & Negative & None
\end{tabular}

Table 2 shows the toxin production potentials of the isolated fungal species from bean flour samples. Aspergillus flavus, $A$. fumigatus, and $A$. niger produced aflatoxins, while Fusarium produced fumonisin. Saccharomyces cerevisae, Mucorspp, Rhizopus spp, shows no toxin production potential 
Table 3: Concentrations of Total Aflatoxins $\left(\mathrm{AFB}_{1}, \mathrm{AFB}_{2}, \mathrm{AFG}_{1} \mathrm{AND} A \mathrm{AFG}_{2}\right.$ ) Found In Sold Beans Flour Using High Performance Liquid Chromatography (HPLC)

\begin{tabular}{|c|c|c|}
\hline $\mathbf{S} / \mathbf{N}$ & SAMPLE & TOTAL AFLATOXIN $(\mu \mathrm{g} / \mathrm{kg})($ AFB1, AFB2, AFG1,AFG2) \\
\hline 1 & $\mathrm{BF} 1$ & 0.024 \\
\hline 2 & $\mathrm{BF} 2$ & 0.088 \\
\hline 3 & BF3 & 0.151 \\
\hline 4 & BF4 & 0.000 \\
\hline 5 & BF5 & 0.000 \\
\hline 6 & BF6 & 0.000 \\
\hline 7 & BF7 & 0.006 \\
\hline 8 & $\mathrm{BF} 8$ & 0.008 \\
\hline 9 & BF9 & 0.091 \\
\hline 10 & $\mathrm{BF} 10$ & 0.024 \\
\hline 11 & $\mathrm{BF} 11$ & 0.000 \\
\hline 12 & $\mathrm{BF} 12$ & 0.039 \\
\hline 13 & $\mathrm{BF} 13$ & 0.019 \\
\hline 14 & BF14 & 0.000 \\
\hline 15 & BF15 & 0.000 \\
\hline
\end{tabular}

Table 3 shows the total level of aflatoxins produced by the fungi species in the bean flour samples. The quantity of aflatoxins ranged from 0.006 to $0.151 \mu \mathrm{g} / \mathrm{kg}$.

\section{Discussion}

The colonization of food crops by fungi species is a process that takes place from farm to fork. As demonstrated in this study, fungal species which include, Fusarium, Mucorsp, Aspergillus fumigatus, Aspergillus niger, Saccharomyces cerevisiae and the Rhizopus, were isolated from the beans flour, thus indicating that microorganisms in raw legumes can be carried into its processed derivative. This agrees with Temba et al., (2017) who reported that certain fungi are found in legumes and legumes based food. Contamination of these produce could either be by biotic or abiotic factors which is reported to be crucial factors that support the growth of fungi and release of toxins in food products (Hill and Waller, 1999), as all the samples had different species of the fungi present. Aspergillus niger, $A$ flavus and $A$. Parasiticus isolated from beans flour samples fluorescence when exposed to Ultraviolet ray, confirming their toxicity or production of toxins in the beans samples, this result is in tandem with the report of Atanda et al., (2011) where he reported that toxigenic mould cultured on Methyl Red Desiccated coconut agar fluorescence under UV light at $360 \mathrm{~nm}$.

Total aflatoxin in the study surpasses the standard regulatory limit of $0.05 \mu \mathrm{g} / \mathrm{kg}$, and this can be related to past studies of aflatoxin in legumes based food by Temba et al., 2017 where he found that leguminous products might be susceptible to contamination by aflatoxin. Fungi are liable to infest agricultural produce due to external environment forces such as insect colonization, skin breakage and presence of sand, dust and debris among 
Badmos et al. / Nig. J. Biotech. Vol. 38 Num. 1 : 68-73(June 2021)

others (Gesinde et al., 2018). It is possible that some of the isolated fungal species from bean flour samples could have originated from any of the aforementioned sources. Also, persistent exposure of food products when on sale could have contributed immensely to the presence of the spores from fungi species in the food product. Due to the weather conditions in the tropics where temperature and relative humidity is high the proliferation of these spores in food is a certain occurrence. Additionally, seeds damaged by insects could serve as a port of entry for fungal infections and toxin production (Dennis, 2002) thereby helping their rapid spread. Therefore, infection is likely to occur at certain crucial conditions with insects. While numerous fungal species are incited in food spoilage all over the globe, it is pertinent to note that organisms isolated from beans flour in the study have been reported to potentially produce mycotoxins such as fumonisin and aflatoxin as confirmed by the toxicity test in the study. Aflatoxins produced by Aspergillus species have been mostly studied because they are the most prevalent and toxic so much so that Aspergillus infections have grown in importance in the last years. Aflatoxin contamination is a serious problem in the tropics which is relatively due to harsh weather conditions that supports the growth of the fungi and it adversely affects our food and feed. Necessary actions and regulations need to be considered to stop the proliferation of these toxin producing organisms in food to enhance food safety and public health.

\section{Conclusion and Recommendation}

Aflatoxin has contributed a great harm to the health of humans and livestock as well as the economy. Commercially sold bean flour is highly consumed in Nigeria and it is very important to know the levels of aflatoxin in order to provide suitable measures to reduce its occurrence in food samples. Aspergillus, Fusarium, Rhizopus, saccharomyces cerevisiae and Mucor were isolated from the food samples. The study therefore concludes that beans flour commercially sold in Abeokuta are contaminated with mycotoxin producing organisms. Some species of the fungi isolated are known to produce toxins like Aspergillus fumigatus and the Fusarium $s p$. Damaged grains should be sorted and eliminated to avoid contamination with mycotoxigenic organisms. Also, stringent laws on raw legume grains should be incorporated and enforced in order to reduce the spread of aflatoxins in food samples.

\section{References}

Abdulwahab, S. A., El-Nagerabi, S. A., and Elshafie, A. E. (2015). Leguminicolous fungi associated with some seeds of Sudanese Legumes. Biodivers.J. 16: 40-48
Atanda, O., Ogunrinu, M. and Olorunfemi, F. (2011). A neutral red desiccated coconut agar for rapid detection of aflatoxigenic fungi and visual determination of aflatoxins. World mycotoxin J. 4:147-155.

Dennis, J. J. (2002). In-Vitro lung delivery of bacteriophages ks4-m and $\varphi k z$ using dry powder inhalers for treatment of burkholderia cepacia complex and pseudomonas aeruginosa infections in cystic fibrosis. J. Appl Microbiol. 110: 106-117.

Gesinde, A. F., Oyawoye, O. M. and Adebisi, A. (2018). Comparative studies on the quality and quantity of soymilk from different varieties of soybean. Pak. J. of Nutr. 71:157-160.

Guinea, J., Escribano, P., Vena, A., Muñoz, P., Del Carmen Martinez-Jimenez, M., Padilla, B. and Bouza, E. (2015). Increasing incidence of mucormycosis in a large spanish hospital from 2007 to 2015: epidemiology and microbiological characterization of the isolates. P126

Hill, A. and Waller, G. (2012). BULIMICS' responses to food cravings: is binge-eating a product of hunger or emotional state. Behav. Res. Ther. 39: 877-886.

Oranusi S. and Braide,W.A (2015). Study of microbial safety of ready to eat food vended on highways: Onitsha- Owerri South East Nigeria. Int. J. Microbiol. Res. 32: 66-71.

Temba, M. C., Njobeh, P. B. and Kayitesi, E. (2017). Storage stability of maize-groundnut composite flours and an assessment of aflatoxin B1 and ochratoxin A contamination in flours and porridges. Food Control. 71: 178-186.

Samson, D. R., Manus, M. B., Krystal, A. D., Fakir, E., Yu, J. J. and Nunn, C. L. (2017). Segmented sleep in a nonelectric, small-scale agricultural society in Madagascar. Am. J. Hum. Biol. 29: 2979.

Kolapo, A.L. and Oladimeji, G. R. (2018). Production and quality evaluation of soy-corn milk. J. Appl. Biosci. 12: 40-45

Klich, M.A., 2002. Identification of common Aspergillus species. Central bureauvoors chimmel cultures, Utrecht, the Netherlands. 1-116

Makun, H.A., Dutton, M.F., Njobeh, P.B., Gbodi, T.A., Ogbadu, G.H. (2012).Aflatoxin contamination in foods and feeds: A special focus on Africa In: Prof. AymanAmerEissa (Ed.) 'Trends in Vital. Fd. \& Control Engnr.' ISBN: 978-953-51-0449-0. 
Badmos et al. / Nig. J. Biotech. Vol. 38 Num. 1 : 68-73(June 2021)

Oluwafemi, F. and Taiwo, V.O. 2004. Reversal of alcoholic extract of African nutmeg, Monodora toxigenic effects of aflatoxin B1 on cockerels by myristica. J. Sci. Food Agric. 84:330-334 